\title{
PEMBERDAYAAN IBU HAMIL DALAM DETEKSI DINI KEHAMILAN RESIKO TINGGI DI PMB BASHORI SURABAYA
}

\author{
Nur Masruroh \\ Universitas Nahdlatul Ulama Surabaya \\ masruroh@unusa.ac.id \\ Yati Isnaini Safitri \\ Universitas Nahdlatul Ulama Surabaya \\ yati@unusa.ac.id
}

\begin{abstract}
Abstrak
Kegiatan pengabdian kepada masyarakat ini dilakukan untuk meningkatkan pengetahuan dan pemahaman tentang deteksi dini kehamilan resiko tinggi di PMB Bashori Surabaya. Waktu pelaksanaan kegiatan dengan jangka waktu 3 bulan. Metode yang diberikan adalah dengan memberikan pengetahuan tentang deteksi dini kehamilan beresiko tinggi. Penyuluhan menggunakan metode ceramah dan tanya jawab.Pengetahuan ibu hamil tentang kehamilan resiko tinggi diukur dengan memberikan pre test berupa kuesioner yang diisi oleh ibu untuk mengetahui tingkat pengetahuan mengenai deteksi dini kehamilan resiko tinggi yang dilakukan sebelum penyuluhan dimulai. Setelah penyuluhan selesai ibu diberi kuesioner yang sama untuk mengukur peningkatan pengetahuannya. Hasil pemberian pengabdian masyarakat menunjukkan adanya peningkatan pengetahuan tentang kehamilan resiko tinggi pada ibu hamil yang sebelumnya $40 \%$ meningkat hingga $77 \%$. Diperlukan peran serta aktif dari ibu hamil dan masyarakat untuk melakukan deteksi dini kehamilan resiko tinggi.
\end{abstract}

Kata kunci : deteksi dini, kehamilan, resiko tinggi

\section{Abstrack}

This community service activity was carried out to increase the knowledge and understanding of high risk early detection of pregnancy at the Surabaya Bashori PMB. Time for the implementation of activities with a period of 3 months. The method provided is to provide knowledge about early detection of high-risk pregnancies. Counseling uses lecture and question and answer methods. Knowledge of pregnant women about high-risk pregnancies is measured by giving a pre-test in the form of a questionnaire filled out by mothers to determine the level of knowledge regarding high-risk pregnancy early detection conducted before counseling begins. After counseling, the mother was given the same questionnaire to measure the increase in her knowledge. The results of giving community service showed an increase in knowledge about high-risk pregnancies in pregnant women who had previously increased $40 \%$ to $77 \%$. Active participation from pregnant women and the community is needed to conduct high-risk early detection of pregnancy.

Keywords: early detection, pregnancy, high risk 


\section{PENDAHULUAN}

Dalam rangka meningkatkan cakupan pelayanan kesehatan kepada masyarakat berbagai upaya dilakukan dengan memanfaatkan potensi dan sumber daya yang ada di masyarakat. Posyandu merupakan salah satu bentuk Upaya Kesehatan Bersumber daya Masyarakat (UKBM), untuk mendekatkan pelayanan kesehatan pada masyarakat melalui wadah keterpaduan lintas sektor dan masyarakat. Yang dikelola dan diselenggarakan dari, oleh, untuk dan bersama masyarakat dalam penyelenggaraan pembangunan kesehatan, guna memberdayakan masyarakat dan memberikan kemudahan kepada masyarakat dalam memperoleh pelayanan kesehatan dasar untuk mempercepat penurunan angka kematian ibu dan bayi (Dinkes Surabaya,2014).

Faktor yang memengaruhi pemberdayaan ibu dalam deteksi dini kehamilan oleh ibu hamil, suami atau keluarga adalah: faktor eksternal antara lain ekonomi, sosial budaya, dukungan sosial, akses informasi, situasi untuk bertindak, jarak rumah dengan posyandu, lingkungan dan faktor internal diri individu yaitu: karakteristik ibu hamil (umur,paritas, pendidikan, pekerjaan, motivasi, niat,otonomi pribadi, pengetahuan dan sikap). Backett (1984) mengatakan bahwa pendekatan risiko dimulai dengan gagasan bahwa ukuran risiko adalah gambaran adanya kebutuhan pelayanan promotif, preventif dan penanganan yang intensif serta adekuat dan tuntas. Kebutuhan ini sebetulnya dapat diramalkan berdasarkan masalah/faktor risiko yang ada, yaitu sebelum komplikasi obstetrik terjadi pada saat persalinan.

Hasil pencapaian deteksi risiko tinggi atau komplikasi yang ditangani/ dirujuk, berdasarkan data dari bidang Kesehatan Masyarakat Dinkes Kota Surabaya, di wilayah kecamatan Wonokromo,Puskesmas Jagir ibu hamil risiko tinggi yang dirujuk 23,25\%, Puskesmas Wonokromo ibu hamil risiko tinggi yang dirujuk 56,78\%, sedangkan Puskesmas Ngagel Rejo ibu hamil risiko tinggi yang dirujuk 63,31\% (Profil Dinkes Kota Surabaya, 2018). Sudah ada peningkatan tetapi belum mencapai target $80 \%$ yang ditargetkan oleh pemerintah 
GAMBARAN

\section{MASYARAKAT}

Praktik Bidan Mandiri milik Bidan Bashori berada di tengah wilayah kota Surabaya yang termasuk di kecamatan Sawahan. Berjarak kurang lebih $5 \mathrm{~km}$ dari kampus A Universitas Nahdlatul Ulama Surabaya. Dengan kunjungan rata rata ibu hamil adalah 40 orang per bulan.

Tingkat pendidikan rata rata di wilayah PMB Bashori sebagian besar $(88,1 \%)$ sudah berpendidikan SMA dan Universitas. Meskipun tingkat pendidikan rata rata masyarakat sudah menengah ke atas, tetapi dari survei awal diketahui bahwa ibu hamil dan kader posyandu belum memahami tentang kehamilan resiko tinggi. Oleh karena itu kegiatan pengabdian masyarakat ini ingin memberdayakan ibu hamil untuk dapat mengerti dan memahami tentang kehamilan resiko tinggi dan cara untuk mendeteksinya.

\section{METODE}

Pelaksanaan dalam program pengabdian kepada masyarakat melalui pemberian penyuluhan tentang deteksi dini kehamilan resiko tinggi kepada Ibu hamil yang datang periksa di PMB Bashori Surabaya ini melalui 3 (tiga) tahap yaitu : a. Pra Kegiatan

1. Rapat strategi pelaksanaan

2. Survei lokasi

3. Persiapan sarana dan prasarana

b. Pelaksanaan Kegiatan

Tahap pelaksanaan kegiatan adalah tahap utama dari program pengabdian pada masyarakat. Sasaran kegiatan pada tahap pelaksanaan adalah ibu hamil yang datang berkunjung di PMB Bashori Surabaya. Untuk pemberian penyuluhan ini, dibagi menjadi 3 sesi kegiatan. Distribusi pelaksanaan adalah sebagai berikut :

1. Penyuluhan tentang kehamilan resiko tinggi :

Pemberian penyuluhan dan pemaparan materi tentang kehamilan resiko tinggi dengan tujuan agar para peserta dapat mengerti dan memahami tentang kehamilan resiko tinggi . Akan disampaikan oleh ketua dan anggota pelaksana kegiatan pengabdian masyarakat dengan menggunakan metode ceramah dan tanya jawab 
2. Penyuluhan tentang Deteksi Dini.

Kehamilan Resiko Tinggi, Pemaparan materi tentang deteksi dini kehamilan resiko tinggi yang bertujuan agar responden dapat memahami dan mengaplikasikan pentingnya melakukan deteksi kehamilan resiko tinggi. Penyuluhan/ pemaparan materi akan disampaikan oleh ketua dan anggota pelaksana kegiatan pengabdian masyarakat dengan menggunakan metode ceramah dan Tanya jawab.
a. Pre Test
b. Post test
c. Pasca Kegiatan

Instrumen evaluasi yang digunakan adalah kuesioner.

\section{HASIL DAN PEMBAHASAN}

1. Gambaran Umum Masyarakat

Kegiatan pengabdian masyarakat ini dilaksanakan dalam bentuk penyuluhan tentang program deteksi dini kehamilan resiko tinggi. Seluruh ibu hamil yang datang berkunjung di PMB Bashori merupakan peserta dalam kegiatan pengabdian masyarakat ini.

Tabel 1 Distribusi Peserta berdasarkan Pendidikan

\begin{tabular}{cccc}
\hline $\mathbf{N}$ & $\begin{array}{c}\text { Pendidika } \\
\text { n }\end{array}$ & $\begin{array}{c}\text { Jumla } \\
\text { h }\end{array}$ & $\begin{array}{c}\text { Persentas } \\
\mathbf{e}\end{array}$ \\
\hline 1 & Menengah & 28 & 80 \\
\hline 2 & Tinggi & 7 & 20 \\
\hline & Total & 35 & 100 \\
\hline
\end{tabular}

Sumber : data primer 2019

Berdasarkan tabel 1 diatas, diperoleh informasi bahwa peserta sebagian besar berpendidikan menengah sebesar $80 \%$ dan yang berpendidikan tinggi hanya $20 \%$.

Tingkat pendidikan responden akan mempengaruhi pola pikir dan perilaku seseorang. Sehingga dalam upaya deteksi dini kehamilan resiko tinggi diperlukan kerjasama dengan masyarakat. Karena program tersebut tidak hanya diberlakukan pada ibu hamil saja dibutuhkan kerjasama serta penyediaan sarana prasarana lingkungan yang mendukung untuk kesehatan. (TNP2K, 2018)

2. Tingkat pengetahuan responden tentang program deteksi dini kehamilan resiko tinggi

Pengetahuan adalah hasil tahu dan ini terjadi setelah orang melakukan penginderaan terhadap obyek tertentu. Dalam kegiatan pengabdian masyarakat ini, para peserta diberikan penyuluhan berupa program deteksi dini kehamilan resiko tinggi. Harapannya dari pemberian penyuluhan ini adalah para peserta dapat meningkatkan pengetahuan dan pemahaman tentang cara deteksi dini kehamilan resiko tinggi, sehingga dapat meningkatkan 
peran sertanya terhadap kegiatan deteksi dini kehamilan resiko tinggi dengan cara ikut melakukan pemantauan terhadap kehamilan.

Penilaian pengetahuan dari para peserta dilakukan dengan metode pre test dan post test. Hasil dari pre test dan post test untuk penyuluhan program deteksi dini kehamilan resiko tinggi adalah sebagai berikut:

Tabel 2 Pre test dan Post Test Pengetahuan tentang pencegahan stunting

\begin{tabular}{cccccccc}
\hline \multicolumn{3}{c}{ Pre Test } & \multicolumn{3}{c}{ Post Test } \\
\hline Tahu & \multicolumn{2}{c}{$\begin{array}{c}\text { Tidak } \\
\text { Tahu }\end{array}$} & Tahu & \multicolumn{2}{c}{$\begin{array}{c}\text { Tidak } \\
\text { Tahu }\end{array}$} \\
\hline $\mathrm{N}$ & $\%$ & $\mathrm{~N}$ & $\%$ & $\mathrm{~N}$ & $\%$ & $\mathrm{~N}$ & $\%$ \\
\hline 14 & 40 & 21 & 60 & 27 & 77,1 & 8 & 22,9 \\
\hline
\end{tabular}

Sumber : data primer 2019

Berdasarkan tabel 2 diatas dapat dinyatakan bahwa hasil pre test peserta yang mengetahui tentang program deteksi dini kehamilan resiko tinggi sebesar 14 orang (40\%), sedangkan berdasarkan hasil post test peserta yang mengetahui tentang program deteksi dini kehamilan resiko tinggi sebesar 27 orang $(77,1 \%)$.

Dilihat dari hasil pre test sebagian besar ibu hamil tidak mengetahui tentang definisi kehamilan resiko tinggi, namun setelah dilakukannya penyuluhan hasil post test hampir seluruh ibu hamil sudah mengerti tentang definisi kehamilan resiko tinggi.
Sehingga terjadi peningkatan pengetahuan masyarakat karena nilai post test lebih tinggi daripada nilai pre test

\section{KESIMPULAN}

Kesimpulan dalam pelaksanaan kegiatan Pengabdian kepada Masyarakat adalah sebagai berikut:

1. Ibu hamil yang berkunjung ke PMB Bashori Surabaya sebagian besar berpendidikan menengah

2. Pengetahuan ibu hamil tentang deteksi dini kehamilan resiko tinggi berdasarkan hasil pre test sebagian besar ibu hamil tidak mengetahui tentang kehamilan resiko tinggi, sedangkan berdasarkan hasil post test hampir seluruh ibu hamil sudah mengerti tentang kehamilan resiko tinggi.

\section{REFERENSI}

Dinas Kesehatan Surabaya. Monitoring dan Evaluasi ANC Terpadu. Dinkes Surabaya 2014 [diunduh 23 Maret 2019]. Tersedia dari: http://dinkes.surabaya.go.id

Kementerian Kesehatan RI. Profil Kesehatan Indonesia 2012. Jakarta: Kementerian Kesehatan RI. 2013 [diunduh 20 Maret 2019]. Tersedia dari : http://www.kemkes.go.id 
Kementerian Kesehatan RI. Upaya menurunkan angka kematian ibu dan kematian bayi perlu kerja keras. Jakarta: Kementerian Kesehatan RI. 2010 [diunduh 23 Maret 2019]. Tersedia dari: http://www.depkes.go.id

Saifudin AB. Buku panduan praktis pelayanan kesehatan maternal dan neonatal. Jakarta: Salemba Medika; 2006.

Sudinkesjakbar. Evaluasi implementasi ANC terpadu dengan HIV dan sifilis. 2014 [diunduh 23 Maret 2019]. Tersedia dari: http://www.sudinkesjakbar.net

Prasetyo B, Had SN. Penerapan antenatal terpadu pada ibu hamil di wilayah kerja Puskesmas Sumobito Kabupaten Jombang. 2013 [diunduh 1 April 2019]. Tersedia dari: http://www.penelitian.unair.ac.id 